\title{
Nós da linha de frente: diálogos sobre o ser da saúde no contexto da pandemia
}

\author{
Munique Therense ${ }^{1}$ \\ Universidade do Estado do Amazonas (Manaus, AM, Brasil) \\ Selma Barboza Perdomo ${ }^{2}$ \\ Universidade do Estado do Amazonas (Manaus, AM, Brasil)
}

Ariane Cristiny da Silva Fernandes ${ }^{3}$

Universidade Federal do Rio Grande do Norte (Natal, RN, Brasil)

\begin{abstract}
O objetivo deste estudo é compartilhar os fazeres e os saberes de profissionais da área da saúde que atuam na linha de frente no enfrentamento da pandemia por Covid-19 em diferentes regiões do Brasil, com base na discussão sobre suas concepções em relação à finitude, sobre os caminhos e as estratégias adotados e/ou necessários para a promoção de sua saúde mental no período da pandemia e sobre a construção de memórias afetivas e/ou traumáticas de suas ações, condutas e desafios enfrentados na linha de frente. O método utilizado foi a criação de um espaço virtual para discussões teóricas, troca de vivências e promoção da saúde mental, que aconteceram em quatro momentos, uma vez por semana, no mês de julho de 2020. As narrativas dos profissionais sinalizaram as dificuldades e os aprendizados relativos ao confronto exaustivo com a morte, bem como as estratégias funcionais e disfuncionais adotadas para fazer frente aos problemas e para a manutenção da saúde mental. Concluiu-se que experimentar o protagonismo de construir coletiva e eticamente uma narrativa sobre as experiências da pandemia mostrou-se dispositivo de cuidado e refazimento importantes para os participantes da ação.
\end{abstract}

Palavras-chave: Covid-19, Saúde mental, Saúde do trabalhador, Profissional de saúde.

We from the front line: dialogues on the being of health in the context of the pandemics

The aim of this study is to share the actions and knowledge of health professionals who work on the front line in fighting the COVID-19 pandemic in different regions of Brazil, based on the discussion about their conceptions in relation to finitude, about the paths and strategies adopted and/or necessary to promote their mental health during the period of the pandemic and on the construction of affective and/or traumatic memories of their actions, behaviors and challenges faced on the front line. The method used was the creation of a virtual space for theoretical discussions, exchange of experiences and promotion of mental health, which took place in four moments, once a week, in July 2020. The professionals' narratives signaled the difficulties and the learning related to the exhaustive confrontation with death, as well as the functional and dysfunctional strategies adopted to face the problems and to maintain mental health. It was concluded that experiencing the protagonism of collective and ethically building a narrative about the experiences of the pandemic proved to be an important care and rebuilding device for the participants in the action.

Keywords: Covid-19, Mental health, Worker's health, Health professional. 


\section{Introdução}

E m maio de 2020, o Brasil foi identificado como o país que contabilizou mais mortes por Covid19 (Lima, 2020), tendo permanecido, depois disso, entre os primeiros colocados no ranking dos países mais afetados. Segundo o Ministério da Saúde (2021), até o fechamento deste artigo, mais de 21 milhões de pessoas já foram infectadas e 598.152 foram mortas pela doença, deixando ainda outros milhares de afetados direta e indiretamente pelas vicissitudes do contexto pandêmico. Tal cenário trouxe altas exigências de trabalho aos profissionais de saúde, além de desdobramentos importantes que ameaçam a sua saúde mental, requerendo planejamento e realização de ações não apenas de enfrentamento e combate da pandemia, como também intervenções que auxiliem os profissionais a adotarem estratégias adaptativas para manejarem com destreza os desafios impostos, sejam eles físicos e/ou emocionais.

O mapeamento dos fenômenos relacionados à saúde mental da população em geral indica estágios diferentes de vivência da experiência de pandemia. Segundo Honorato et al. (2020), a fase pré-pandemia foi caracterizada por estados de ansiedade e depressão. Já a fase pandêmica, pela acentuação desses quadros e o surgimento de problemas decorrentes do agravamento da crise em saúde e do isolamento social, tais como violência doméstica e vulnerabilidade econômica. Ainda segundo os autores, para a fase pós-pandemia estipula-se o surgimento de adoecimentos relacionados à exaustão emocional decorrente das vivências traumáticas e da sobrecarga de trabalho.

Nesse contexto, os profissionais de saúde, em especial, aglutinam, em seus cotidianos de trabalho, alguns elementos disparadores de adoecimento. A respeito das implicações psicológicas que acometem esse nicho populacional, a literatura nos revela a constante preocupação desses profissionais frente ao risco de serem infectados, medo de adoecer ou morrer, possibilidade de infectar outras pessoas, cansaço diante da sobrecarga de trabalho, fadiga, frustração por não conseguir salvar vidas e sofrimento, dada a constante exposição às mortes em larga escala (Schmidt et al., 2020). São disparadores que se configuram como fatores de sofrimento psíquico conjugados àqueles relacionados às fraturas sociais acentuadas pela pandemia. Por isso, estudos alertam quanto à possibilidade do aumento de casos de suicídio e agravamento de quadros de adoecimento psíquico (Kavoor et al., 2020; Mamum \& Griffiths, 2020).

Frente ao cenário existente e àquele posto no horizonte de cuidados, observam-se diversas iniciativas de promoção e prevenção em saúde mental. Duan e Zhu (2020) discorrem sobre a relevância da Tecnologia da Informação e dos diferentes espaços fomentados para viabilizar a comunicação, em especial a escuta qualificada e o atendimento psicológico remoto, como ações importantes para o acolhimento da dor e das queixas relativas à saúde mental de profissionais da área da saúde em meio à pandemia.

Em estudo realizado na China por Bao et al. (2020), observou-se que os profissionais da saúde que cuidam de pacientes graves infectados pela Covid-19 sentem medos e inseguranças, sofrem o luto pelas inúmeras perdas e, não raro, tornam-se vulneráveis, apresentando dificuldades no manejo de suas próprias emoções. Isso levou a Comissão Nacional daquele país a desenvolver diretrizes para as autoridades locais implementarem intervenções psicológicas para pacientes e profissionais da saúde durante o surto iniciado em 2019. Nesse mesmo sentido, a Universidade de Pequim empenhou-se em elaborar um manual de saúde mental para o público, descrevendo como lidar com o estresse e outros problemas psicológicos decorrentes da pandemia. Para os autores supracitados, o programa de saúde mental desenvolvido na China faz parte das estratégias de contenção da doença. Além de o governo chinês esforçar-se em manter atualizadas as informações epidemiológicas e das medidas de contenção instauradas, foi crescente a disponibilização de psicólogos e psiquiatras usando a internet e mídias sociais para compartilhar estratégias para lidar com o estresse psicológico. Dentre as variadas medidas de prevenção de contágio, a população em geral e especialmente os profissionais da área da saúde foram incentivados a procurar atendimento nos centros de atendimento psicológico e departamentos de Psicologia de universidades para acolhimento por telefone ou espaço virtual. 
A identificação de ações internacionais direcionadas aos profissionais de saúde da linha de frente instigou a reflexão a respeito das seguintes questões: qual a relação/concepções/postura/reflexões dos profissionais brasileiros da área da saúde quanto à finitude da vida frente à pandemia? Quais as estratégias de enfrentamento adotadas para a promoção de saúde mental do trabalhador? Quais memórias marcaram sua atuação na linha de frente? Para buscar as respostas para esses questionamentos e com o intuito de produzir subsídios que ampliassem a compreensão sobre as nuances dos fenômenos em saúde mental provocados pela pandemia, este artigo apresenta os resultados oriundos da análise da experiência Nós da Linha de frente: diálogos sobre o ser da saúde no contexto da pandemia, ação de extensão universitária executada pela Universidade do Estado do Amazonas (UEA) em parceria com o Laboratório de Estudos em Tanatologia e Humanização das Práticas em Saúde da Universidade Federal do Rio Grande do Norte (LETHS/UFRN). O objetivo da ação foi promover um espaço virtual de compartilhamento de vivências da linha de frente e de promoção da saúde mental.

É válido ressaltar que muitos dos profissionais participantes do projeto estão lotados em instituições situadas em estados que passaram por períodos diferentes da crise instalada na saúde. A título de exemplo, tem-se que, no Amazonas, o colapso da saúde pública na capital foi deflagrado desde metade de abril (Carvalho, 2000), ao passo que, no interior, no final de maio observaram-se os indicativos de crescentes números de casos (Marques, 2020), coincidindo com a realidade de algumas outras capitais do Brasil, como a do Rio Grande do Norte (Globo Notícias, G1, 2020). A princípio, poder-se-ia pensar que as singularidades de cada região demandavam exclusivamente práticas regionalizadas. Contudo, em que pese o importante reconhecimento dessa pluralidade, compreende-se que o compartilhamento de ideias, percepções, iniciativas e saberes constitui-se em ação potencialmente capaz de fortalecer os trabalhadores e sua saúde mental em contexto de pandemia. Pretende-se, com este artigo, proporcionar uma compreensão ampliada da experiência de ser trabalhador da saúde no contexto da pandemia.

Dessa forma, este relato de experiência tem como objetivo compartilhar os fazeres e os saberes de profissionais da área da saúde que atuaram na linha de frente no enfrentamento da pandemia por Covid-19 em diferentes regiões do Brasil, com base na discussão sobre suas concepções em relação à finitude, sobre os caminhos e as estratégias adotados e/ou necessários para a promoção de sua saúde mental no período da pandemia e sobre a construção de memórias afetivas e/ou traumáticas de suas ações, condutas e desafios enfrentados na linha de frente.

\section{Método}

O Nós da linha de frente foi pensado como uma forma de execução do projeto de pesquisa intitulado A história como prática social: navegando em biografias educativas e da área da saúde, aprovado pelo Parecer n⿳0 4.003.013, emitido pelo Comitê de Ética em Pesquisa da Universidade do Estado do Amazonas (CEP/UEA). Diferentes profissionais de saúde que exerceram suas funções no enfrentamento da pandemia, tais como em Medicina, Enfermagem, Psicologia, Terapia Ocupacional e Fisioterapia, foram convidados a dialogar com outros atores da saúde e estudantes acerca da condição de ser trabalhador no contexto da pandemia de Covid-19. A operacionalização do projeto de pesquisa mencionado, por meio da ação de extensão universitária, e a análise dos resultados cultivam a noção central de que a escrita da História é também uma prática social. Ao terem suas experiências registradas, esses profissionais, atores principais desse cenário, puderam assumir o lugar como protagonistas na narrativa de um momento tão peculiar, compondo a tessitura viva de palavras capazes de traduzir o processo experienciado enquanto agentes ativos e, ao mesmo tempo, passivos das ações, afetações e transformações.

A proposta foi ofertada ao público-alvo de forma gratuita, por meio de um formulário de inscrição on-line. Ao todo inscreveram-se 55 participantes, representando 15 estados e 19 municípios brasileiros. Os encontros virtuais aconteceram via plataforma Google Meet, nos dias 7, 14, 21 e 28 de julho de 2020, das $19 \mathrm{~h}$ às $21 \mathrm{~h}$, e tiveram quatro eixos centrais de discussão 
teórica e experiencial: (a) Finitude e impermanência na linha de frente; (b) Pós-pandemia e saúde mental dos profissionais da linha de frente; (c) Trilhas para a promoção da saúde mental; e (d) Memórias da linha de frente. Cada encontro contou com a condução de três profissionais, sendo o primeiro, nomeado Debatedor, responsável por trazer ao grupo provocações oriundas de questões centrais do tema em debate, e os outros dois, nomeados Conversadores, incumbidos de compartilhar suas experiências de trabalho na linha de frente durante a pandemia. Ao todo foram 4 debatedores/as e 8 conversadores/as. Os demais participantes do encontro tinham liberdade para interagir via chat da sala virtual ou acionamento do áudio/vídeo pessoal.

Aos profissionais convidados foi apresentado o Termo de Consentimento Livre e Esclarecido (TCLE) com vistas a obter o assentimento, para que as narrativas pudessem ser publicadas neste artigo. Os fragmentos de falas dos participantes estarão identificados no texto pelas iniciais dos nomes seguidas da data.

\section{Resultados}

Os resultados estão organizados e foram analisados com base nos títulos dados a cada encontro virtual e do mote discursivo delimitado.

\section{Finitude e impermanência na linha de frente}

No encontro intitulado Finitude e impermanência na linha de frente, a provocação temática de estreia versou sobre o luto disparado pelo contexto pandêmico, principalmente no que se refere ao legado histórico e existencial em construção, com base no enfrentamento das adversidades inerentes a esse contexto. Na perspectiva da debatedora, a crise de saúde carregou em seu cerne uma ameaça invisível ao mundo presumido dos profissionais, que se refere, segundo Parkes (2009), à cotidianidade previsível sob a qual ampara-se nossa rotina, nossas crenças, nossos valores, nossos laços de afeto e a edificação do nosso lugar na vida e nas relações, bem como à estruturação do nosso senso de significado e de propósito existencial. Para a debatedora, a ruptura do mundo presumido foi ocasionada pelo confronto avassalador com a fragilidade e a finitude humanas, o que levou muitos trabalhadores a deparar-se de maneira cruel e recorrente com a morte, um dos maiores tabus da formação e da trajetória profissional.

Fomos apresentados à estatística de que, para cada pessoa morta, estima-se entre 4 e 14 pessoas enlutadas. Assim, no cenário atual, há diversos fatores complicadores do processo de enlutamento, considerando as indicações de Crepaldi et al. (2020), Shear (2015) e Worden (2013), a exemplo das restrições sanitárias à realização dos ritos fúnebres, como culturalmente os conhecemos; o impedimento da construção familiar de uma história de cuidado ao paciente no decurso da doença e hospitalização; as mortes múltiplas, inesperadas e solitárias; os déficits de apoio social/familiar devido às restrições impostas pela quarentena, dentre outros fatores.

Ademais, a discussão apontou as impermanências no ambiente de trabalho que potencializaram as chances de os trabalhadores desenvolverem lutos traumáticos. Incluiu-se nesse âmbito o enlutamento pelos pacientes mortos em grande número, o defrontar-se sistemática e repetidamente com um desfecho clínico diverso do que se almeja na área da saúde, o desafio de manter a rotina da linha de frente, a despeito do adoecimento e da morte de colegas de trabalho, e os sentimentos acentuados de desamparo e desesperança incrementados pelas notícias e decisões da gestão pública que ampliaram as dificuldades. Desta feita, as reflexões a respeito da morte e do processo de morrer foram o mote do encontro. Evidenciou-se o convite inusitado e, simultaneamente, doloroso que a situação pandêmica endereçou a cada um, defrontando-nos absurdamente com a condição humana, portanto finita, com os flagelos sociais, com a vulnerabilidade da nossa existência, com a necessidade de rever rotinas, hábitos, repensar e/ou redirecionar nossos valores éticos e morais, e de nos cuidarmos e cuidarmos uns dos outros.

Mais do que um evento puramente biológico, uma construção sócio-histórica-cultural e simbólica, o confronto com a morte em larga escala suscitou indagações a respeito da 
impertinência de o trabalho em saúde sustentar-se no ocultamento e/ou banimento da finitude enquanto condição definidora da existência humana. Nesse sentido, a facilitadora pôs no centro do debate de ideias a insustentabilidade do discurso de onipotência diante da vida e da morte sabido pilar do trabalhador da saúde - uma vez que dele podem derivar os riscos para o adoecimento mental. Dentre eles, destacou-se a síndrome de burnout, distúrbio emocional caracterizado pela extrema exaustão oriunda da experiência de trabalho, e a fadiga de compaixão, termo cunhado por Figley (1995) para designar exaustão biopsicossocial causada pela vivência de intensa compaixão desacompanhada de percepção de ser recompensado.

O encontro foi encerrado com a partilha poética a respeito dos necessários espaços de cuidado ao profissional da linha de frente:

Os nós enfrentados na linha de frente; o nós que fomos provocados a aprender a ser diante dos desafios que a pandemia nos apresentou; o nós que desata nós e forma laços de solidariedade, respeito à vida e acolhida; o Nós da linha de frente foi tecido com zelo para proporcionar abrigo diante das dificuldades do estar na linha de frente no combate à pandemia, para fazer frente às necessidades de cuidado dos nossos pacientes e para preservar e cuidar da sua saúde mental em contexto tão adverso (A.F., 7 jul. 2020).

A essa provocação temática seguiu-se a fala de um dos profissionais de saúde convidados, um coordenador setorial do hospital de trauma temporariamente adaptado para atender pacientes com Covid-19, para partilhar sua experiência. Sua fala inicial enfatizou que a pandemia promoveu a valorização de algumas categorias profissionais na área da saúde, para além da categoria médica. Utilizando-se do exemplo da fisioterapia intensivista, o conversador ressaltou ter percebido diferença na forma como tais trabalhadores foram descritos por gestores e população em geral, bem como na frequência de vezes com que eram citados e solicitados.

$\mathrm{Na}$ função de coordenador, observou que os profissionais da linha de frente manifestaram pavor prévio à chegada de pacientes contaminados, tendo sido necessária intervenção da equipe de psicologia na oferta de suporte àqueles que atuariam direta e continuamente no manejo dos pacientes infectados, como fisioterapeutas, que tratam diretamente das secreções e dos fluídos oriundos do quadro de infecção pelo novo coronavírus. Na sua perspectiva, o fato de os trabalhadores terem ocupado o lugar de espectadores da situação de trabalho de outros locais (estados ou instituições) mobilizou emoções intensas e impactou a vivência prévia da linha de frente. Somou isso às características do vírus, cuja identificação segura ainda se encontrava em andamento, e às questões de infraestrutura do sistema de saúde.

Eu brinco com o pessoal que o lugar mais seguro do hospital é a UTI Covid, porque, lá, a gente sabe que o vírus está. Só que começa a acontecer que o Covid vai sair dos ambientes próprios dele, porque não tem mais leito para acomodar os pacientes. Aí começa a aparecer na enfermaria, começa a aparecer no pronto-socorro e em áreas que a população tá mais vulnerável. Eu perdi uma colega há três semanas que não atua em UTI Covid. Isso se torna assustador . . . O carro tá andando e a gente tá trocando o pneu do carro andando. A ciência tá acompanhando os acontecimentos. Será que a precaução é contato? Será que a precaução é aerossol? Onde a gente vai se precaver mais? (N. M., 7 jul. 2020).

Para o debatedor, essas questões trouxeram impacto nas vivências familiares, principalmente no que tange aos rituais comuns, como aniversário, hora de comer e dormir. $\mathrm{Na}$ perspectiva dele, não há dissociação entre o trabalhador e o sujeito que tem família. Ele é, ao mesmo tempo, uma pessoa inserida nesses dois cenários, o que faz com que, inevitavelmente, as experiências da linha de frente interfiram de forma dramática nos afetos direcionados à família, no trânsito entre domicílio e trabalho e no risco de transmissão do vírus.

Trouxe, ainda, a reflexão de que percebeu a preocupação da população em geral com o combate à pandemia. Seguindo a trilha da visibilidade dos profissionais que apresentou no início da fala, explanou que a sociedade civil e as pessoas jurídicas mobilizaram-se na cidade para providenciar EPIs para os trabalhadores da linha de frente, o que, para ele, foi um diferencial 
desse momento. Entende que os problemas de infraestrutura da saúde pública já existiam anteriormente, mas que o momento atual escancarou e potencializou as dificuldades nas redes pública e privada de saúde, o que pode ter sido catalisador das contribuições financeiras de empresas e/ou pessoas físicas para providenciar equipamentos. Tal discussão nos remete às questões referentes à mercantilização da saúde e às adversidades que integram os serviços de saúde pública e o cotidiano dos trabalhadores, tal qual descritas por Travagin (2017).

Suas conclusões versaram sobre a resposta de sofrimento do profissional da linha de frente, ao observar que um grande contingente de óbitos se encaixava na categoria de morte evitável. Dentre os motivos pelos quais o óbito encontra-se nessa categoria estariam a falta de leito, a contratação de recursos humanos pouco capacitados e respiradores impróprios ou em falta. Contudo, para ele, a morte com maior impacto é a morte dos colegas que, muitas vezes, atravessam o processo de morte cientes do agravamento do quadro e das implicações disso. A morte dos colegas teria, para ele, o potencial de desvelar a própria finitude, o que se coaduna com o que fora posto pela provocadora temática no início do encontro.

Pós-pandemia e saúde mental dos profissionais da linha de frente e Trilhas para a promoção da saúde mental

Esta seção condensa as narrativas emergentes nos segundo e terceiro encontros, cujas temáticas foram intencionalmente organizadas de forma sequencial para conseguir abarcar o que os trabalhadores da linha de frente vislumbravam como perspectiva de futuro pós-pandemia e, em seguida, mapear as estratégias de promoção de saúde mental traçadas com base nessas presunções.

No encontro denominado Pós-pandemia e saúde mental dos profissionais da linha de frente, a provocação temática sobre o cenário pós-pandemia foi organizada pela conversadora com o apoio da perspectiva de que, para os trabalhadores da linha de frente, as hipóteses acerca do futuro precisam ser compreendidas com base nos acontecimentos da pandemia e os ocorridos antes dela. Nesse sentido, o futuro não foi representado como ruptura temporal, mas como continuidade entre os fenômenos do passado e do presente. Dentre os elementos mais significativos no alinhavo dessas temporalidades, a conversadora destacou a fragilidade do planejamento estratégico de combate à pandemia e os efeitos dela como fator de impacto na saúde mental dos profissionais da linha de frente.

Para a facilitadora, as diretivas do Ministério da Saúde deveriam cumprir função primordial na organização das práticas de combate à pandemia a serem planejadas e executadas, sendo elemento motor para a resposta efetiva, a solidez e a continuidade das intervenções exigidas por uma situação pandêmica. Logo, os desencontros entre os discursos do Ministério da Saúde e do governo federal, as sucessivas substituições de ministros da saúde, a desautorização pública e sistemática dos comandos ministeriais e os conflitos gerados pela fragilidade das comunicações oficiais dos gestores, incluindo a veiculação de notícias falsas, foram apontados como catalisadores de estresse laboral que acentuaram o sofrimento psíquico dos profissionais da linha de frente.

Segundo as narrativas compartilhadas no encontro, os trabalhadores da saúde compreenderam a gravidade do cenário de crise global antes do vírus ser identificado no Brasil; contudo, a experiência vivida por outros países e amplamente retratada pela mídia nacional e internacional não foi suficiente para que fosse elaborado um plano de trabalho seguro e articulado em rede, englobando as esferas federal, estadual e municipal. Isso gerou o aumento na percepção de sobrecarga de trabalho em virtude da debilidade do planejamento e da superexposição aos riscos de contaminação, essa última forjada também pelo descrédito da população atendida em relação à necessidade de obediência às diretrizes de biossegurança.

As decisões governamentais em relação ao Sistema Único de Saúde (SUS) antes do início da pandemia também foram destacadas como elementos de significativo impacto para o contexto pandêmico e pós-pandêmico. Os cortes das verbas destinadas à saúde pública, ocorridos antes da pandemia, mostraram-se contrários à importância e à centralidade do SUS, visto pelos 
participantes do projeto como o principal sistema encarregado de responder com rapidez e eficiência às demandas da população em geral. As narrativas nos encontros remeteram-nos ao double bind, dilema da comunicação em que ao indivíduo são transmitidas duas ou mais informações contraditórias, em que ambas são tomadas como válidas, porém uma nega a outra (Bateson et al., 1956). A existência do double bind catalisou a autopercepção de fadiga, esgotamento físico e mental e acentuou o sentimento de medo, insegurança e desamparo.

As conclusões sobre as perspectivas de futuro foram então conjecturadas com base na interrogação de outros futuros possíveis em caso de passado e presente vivenciados de forma diferente da narrada anteriormente. Levantou-se o questionamento a respeito da evitabilidade e/ou da possibilidade de mitigar o sofrimento vivenciado pelos trabalhadores, incluindo aqueles que precisaram manter-se na linha de frente após a perda de familiares e de colegas de trabalho. A convidada nos provocou com pergunta emblemática: "Quem sabe não seria diferente? Se a gente estivesse em um outro contexto político, as coisas seriam um pouco menos doloridas? Quem sabe não seria diferente?” (M. A., 14 jul. 2020).

A discussão coletiva atingiu seu ápice com os questionamentos relativos à inadequação do uso dos arquétipos do super-herói e do soldado que, de acordo com as debatedoras, são dotados de superpoderes, de riquezas /ou de armas potentes para se defender e destinar sua vida ao combate, o que diverge substancialmente da realidade dos profissionais de saúde. Diferente das/dos personagens das histórias em quadrinhos ou dos campos de batalha, os trabalhadores da linha de frente não desfrutam de mentores, de armas superpotentes, tampouco de superpoderes ou de um ego auxiliar capazes de sustentá-los em um contexto assistencial desafiador e livrá-los dos perigos intrínsecos ao fazer profissional. Os arquétipos utilizados para nomear os trabalhadores da saúde apresentam-se contraproducentes à ponderação realística de suas limitações, ao reconhecimento e atendimento efetivo de suas necessidades demasiadamente humanas.

Além disso, segundo as conversadoras, as informações oficiais confusas e a reprodução de notícias falsas a respeito do novo coronavírus geraram a percepção de indefinição do objeto de combate, constituindo um "vilão" imprevisível. Reconhecendo a ausência de superpoderes e a multifaceta indefinida do inimigo a ser vencido, os profissionais da saúde experimentaram a inadequação da alegoria do super-herói em suas vivências, ao passo que assistiram à reprodução massiva desse ideal de heroísmo nas camadas sociais e canais midiáticos. O conjunto formado pela expectativa social de agir como super-heróis em contraste com a realidade de serem humanos aguçou sintomas de adoecimento psíquico, tais como os ansiogênicos ou depressivos. Na perspectiva da segunda conversadora, diferente dos super-heróis, os trabalhadores da linha de frente foram interpelados a reconhecer sua humanidade, e seus sintomas expressaram as contradições da realidade e as reações de vida diante delas. Em certas circunstâncias, tal cenário impulsionou o trabalhador da linha de frente a buscar formas de corresponder às exigências de trabalho na pandemia, ou subjetivar-se com o apoio delas, sendo possível perceber o aumento do uso de opioides entre profissionais da saúde que procuram a rede de atenção psicossocial:

Não somos como os super-heróis, que não são humanos e, quando o são, contam com grandes forças e extravagâncias que a gente, na vida cotidiana, não tem. Ao contrário dos heróis, a nossa humanidade dói. E para lidar com essa dor da humanidade de ver pessoas morrendo, de ver pessoas próximas, de ver os colegas que não estão bem . . . a gente vai desenvolver sintomas, como todas as pessoas. Então, a meu ver, estar ansioso, estar com humor deprimido, é sinal de que a vida pulsa dentro da gente. Seria esquisito se a gente não tivesse . . . A gente tem esse direito de sentir essa dor, de compartilhar essa dor. A gente tem direito de não ter superpoderes. $\mathrm{O}$ que a gente tem visto no CAPS [Centro de Atenção Psicossocial] aumentou um pouquinho e minha suposição é que vai aumentar mais, são profissionais de saúde que têm tido muito problema com uso de opioides ... Eu acho essa escolha tão simbólica! O que é o opioide? É um medicamento que atua no alívio da dor ... O opioide atua para não sentir. A minha interpretação é que parece dizer "eu não tenho direito a não ser super-herói, então vou usar opioide para esquecer meu sofrimento e voltar a trabalhar". Entre um descanso e outro na sala de conforto, aplicam um pouquinho (J. O., 14 jul. 2020). 
Tal realidade mostra o sofrimento dos trabalhadores que vivenciaram um cenário de tentativa de subjetivação com base em ideais não humanos, amplificada pela tensão gerada entre o saber e o sentir, características das formações e atuações em trabalhos nas áreas da saúde (Bonet, 2004).

No seguimento do encontro, a terceira conversadora trouxe a perspectiva do olhar dos gestores de setores menores, que observaram com apreensão as notícias sobre a alta taxa de transmissibilidade do Sars-cov-2 e a ausência de respostas rápidas e estratégicas do sistema de saúde. Segundo ela, a assistência intensivista na região Norte chegou a ser de menos de um leito de Unidade de Terapia Intensiva (UTI) por pessoa, ao passo que, no sistema privado, subiu para mais de quatro leitos. A experiência vivenciada foi de incongruência entre as falas oficiais dos gestores, que afirmaram estar preparados para atender as demandas da crise de saúde, e a realidade, em que as ações de resposta só começaram a ser executadas, sem mobilização em rede, após confirmação do primeiro caso em solo estadual. Logo, disponibilização de Equipamentos de Proteção Individual (EPI), vagas em leitos hospitalares, paramentação e estruturação de UTI e profissionais especializados foram itens que, a priori, pareciam óbvios e fora de negociação, mas, no cotidiano, transformaram-se em objetos de disputas gerenciais.

Dentre os principais desafios, a conversadora destacou que a estrutura de UTI, fluxo de pacientes e número de óbitos mostraram-se significativamente diferentes daquilo que é vivenciado na graduação e na rotina hospitalar fora do cenário pandêmico. Para ela, os profissionais da linha de frente experienciaram reações típicas de pânico, sendo necessário abordar estratégias de defesa contra o sofrimento ocasionado pelo trabalho. Dentre essas, foram enfatizadas as estratégias coletivas e institucionais, tais como reprodução de orientações em relação à paramentação e à desparamentação, cotas privadas para providenciar os EPIs e organização laborativa que contemplasse a integração e execução do serviço por profissionais com mais tempo de trabalho que acompanhavam aqueles recém-contratados, de forma a tornar o trabalho menos ameaçador. Dentre as estratégias de promoção de saúde mental, os profissionais incorporaram estratégias individuais e coletivas, tais como meditação antes do plantão, orações e mudança provisória de domicílio para a proteção dos seus familiares. Segundo Vivian et al. (2019), as estratégias coletivas são úteis porque conseguem abarcar aquilo que as estratégias individuais não dão conta, favorecendo coesão do grupo de trabalho e mudanças nas práticas laborais.

Destacam-se ainda as dificuldades vivenciadas em virtude de atrasos no pagamento dos honorários laborais, fato que se mostrou como mais um elemento de sofrimento gerado pelo dilema do double bind.

Isso foi triste, porque a mídia tratava a gente como super-herói, mas, por outro lado, a gente pedia, pedia, pedia o pagamento, de ter que ir até a Secretaria de Saúde toda semana, para explicar que precisava pagar os enfermeiros contratados que estavam sem receber. Então, foi muito difícil... (S. O., 14 jul. 2020).

A narrativa evidencia o problema gerado por decisões de gestões que mostram estratégias contraditórias sobre manter a proteção à vida dos contaminados e desproteger os profissionais da saúde que oferecem a assistência necessária aos primeiros. A experiência corrobora o entendimento de que o sofrimento que produz a necessidade de criação de estratégias interligase com o trabalho (Dejours, 2017; Dejours et al., 2018).

No terceiro encontro, denominado Trilhas para a promoção da saúde mental, a provocação temática organizada pela conversadora trouxe o fato de os profissionais da linha de frente, ao mesmo tempo em que precisaram reforçar discursivamente o controle rigoroso do isolamento social, não tiveram, em seu cotidiano, a opção de manterem-se isolados, haja vista desenvolverem trabalho essencial. Suas rotinas foram estruturadas para manterem-se na ativa, sem, no entanto, gozarem dos conhecidos caminhos de escape e equilíbrio mental para suportar as demandas de trabalho. Para a conversadora, isso pode ter gerado, por vezes, comportamentos semelhantes aos 
observados em consumo, quando, na emergência de uma realidade repleta de mensagens conflitantes, números vertiginosamente altos, estratégias de combate pouco estruturadas e derivadas de mensagens simplistas e taxativas, há a adoção de comportamento de risco por parte de um nicho populacional específico.

A trilha para a promoção da saúde mental apresentada pela conversadora foi a da política de redução de danos, apontada por Machado e Boarini (2013) como possibilidade de considerar e entender as complexidades da realidade e dos comportamentos humanos no cenário de pandemia. Para tanto, a conversadora resgatou o uso da mandala de prevenção, sugerindo uma mandala da Covid-19 como modelo de prevenção biopsicossocial para delinear os ganhos e os riscos postos em balança, e entender as decisões individuais de cada profissional de saúde quanto aos comportamentos de proteção e de risco. Assim, a redução de danos foi considerada como caminho possível para a redução de infecção por SARS-COV-2 e aumento da sanidade mental de quem estava na linha de frente.

A alegoria da mandala foi bem recebida pelos participantes. Os conversadores que compartilharam experiências utilizaram-se dela, em seguida, para expor as trilhas percorridas por eles e por colegas do entorno. Os conversadores indicaram os itens da mandala como flexibilizadores da tensão estruturante do trabalho da linha de frente. Dentre os itens apareceram:

1. Rituais de proteção: paramentação e desparamentação, limpeza na saída do trabalho e na chegada de casa, manipulação de sapatos;

2. Psicoterapia on-line: busca por auxílio profissional para dar conta do sofrimento gerado pela pandemia;

3. Manter padrão de sono: controlar horários de sono para conseguir promover repouso ao corpo;

4. Grupos de interesses específicos: leitura on-line (participar de discussões de livros que não estão relacionados ao trabalho da linha de frente) ou clube de vinho;

5. Recursos holísticos de relaxamento: velas aromáticas, meditar ao som de sinos tibetanos, pilates em casa com acompanhamento remoto, imersão em água quente em piscina desmontável;

6. Reencontro em grupos pequenos: manter contato com pequenos grupos de pessoas cujo vínculo é considerado essencial;

7. Apoio do núcleo familiar: companheiros domésticos e filhos foram catalisadores de coragem e disposição para o enfrentamento da pandemia. Interessante que o bemestar dos filhos em isolamento social foi considerado, ao mesmo tempo, um desafio a ser vencido e um ponto de equilíbrio para se restabelecer;

8. Autoconhecimento, conforme expresso nas palavras a seguir:

Um osso, quando quebra, pra colar, ele precisa de estabilidade ... Não importa de onde venha. A gente precisa também dessa estabilidade. A primeira coisa é conhecer um pouco mais de si mesmo, conhecer o que torna a gente mais forte, o que nos faz bem. A primeira coisa é assumir as paranoias, se conhecer. Isso nos dá estabilidade. A segunda coisa que o osso precisa é biologia, suprimento nutrício. O osso precisa que chegue sangue ... Na COVID todo mundo sofreu dores, fraturas com perdas de gente querida. Aí a gente teve que pensar o que nos torna fortes, qual o nosso suprimento nutrício (A. C., 21 jul. 2020).

Ao observar as trilhas destacadas, identificamos que, diferente do segundo encontro, as estratégias de enfrentamento e defesa do sofrimento causado pelo trabalho criadas e elencadas foram majoritariamente individuais. Tal cenário não é novo, remetendo-nos ao que Vivian et al. (2019) já havia identificado em docentes da pós-graduação. Os itens da mandala que apareceram mostram a participação de outras pessoas, contudo, não trouxeram os colegas de trabalho como agentes estratégicos, demarcando os esforços individuais como prioritários para se manter em 
equilíbrio e/ou saudável mentalmente. Nas falas desse encontro, também não foram observadas estratégias institucionais formais para subsidiar o enfrentamento do contexto pandêmico.

Memórias da linha de frente

O movimento reflexivo de quem deseja dar forma às recordações e aos sentimentos por meio da palavra, em um espaço de construção coletiva, marcou a partilha das memórias dos profissionais da área da saúde que atuaram na linha de frente no enfrentamento da Covid-19 no último encontro on-line. Nesse ensejo, estávamos munidas de imenso senso de responsabilidade em acolher narrativas preciosas, com o dever de registrar, em um trabalho acadêmico, os relatos e as nuances da vida de pessoas que vivenciaram os múltiplos aspectos da pandemia, redescobrindo-se e reinventando o modo próprio de atuar em suas profissões.

Nossa inquietação, no último encontro, expressava-se na questão: se o que é lembrado são as vivências percebidas e elaboradas pela reflexão, o que os conversadores daquela noite escolheriam para perpetuar na história de suas vidas, considerando o auge do período pandêmico? Como pontua Bosi (1994, p. 21):

Uma lembrança é um diamante bruto que precisa ser lapidado pelo espírito. Sem o trabalho da reflexão e da localização, ela seria uma imagem fugidia. O sentimento também precisa acompanhá-la, para que ela não seja uma repetição do estado antigo, mas uma reaparição.

A ação de extensão como espaço de cuidado de profissionais da área da saúde nesse período levou-nos à dimensão paradoxal de sermos, ao mesmo tempo, sujeitos e objetos de intervenção. Sujeitos enquanto perguntávamos e tentávamos de alguma forma acessar as percepções e os sentimentos daqueles que estavam na linha de frente; e objetos quando escutávamos, acolhíamos as suas narrativas, carregando nesse ato o cuidado de guardar e perpetuar suas lembranças desse período que deixam marcas na história e reorientam o sentir e o fazer profissional.

À época de realização do projeto, passados quatro meses de experiências no enfrentamento da pandemia, os profissionais da área da saúde foram convidados a refletir sobre as memórias marcantes que cultivavam até o momento, assim como aquelas que gostariam de guardar como algo simbólico. Partindo do que foi postulado por Halbwachs (2003), entendemos que a memória é um processo de reconstrução do passado com base no presente, e deve ser analisada sob dois aspectos: o primeiro refere-se ao fato de que, ao falarmos de memória, não estamos nos referindo a uma repetição linear de acontecimentos e vivências no contexto de interesses atuais; e o segundo é que ela diferencia-se dos acontecimentos e vivências que podem ser evocados e localizados em um determinado tempo e espaço, envolto num conjunto de relações sociais. Sendo assim, o autor afirma que a memória é a reconstrução, vivificação e ressignificação do ocorrido.

O autor supracitado afirma que, para se recordar, é necessário que o nosso pensamento não deixe de concordar, em certo ponto, com os pensamentos dos outros membros do grupo. Desse modo, esquecer determinado período, fato, evento de nossa vida, é perder também o contato com aqueles que compunham nosso grupo social. Nesse mesmo sentido, a memória individual, conceituada por Halbwachs (2003), corresponde a um ponto de vista da memória de um grupo que compartilhou um evento.

Partindo dessa premissa, entendemos que as memórias dos profissionais da saúde que participaram desse espaço de partilha, ainda que recentes, valorizam e representam, em parte, a narrativa de seus pares, que formam, no dia a dia de trabalho, o seu corpo social. Compreendemos também o espaço de partilha como um instrumento que tornou viável o contato com diferentes protagonistas de um mesmo contexto profissional, mitigando o esquecimento do que foi apreendido nesse período.

Logo, adentrar pelas memórias desses profissionais nesse momento crítico exigiu certa ousadia, apropriada às descobertas, e alta dose de sensibilidade e respeito para com os conteúdos encontrados. Entendemos, apoiadas em Souza (2004), que a construção da escrita narrativa 
surge da relação paradoxal entre o passado e as projeções do futuro, potencializando-se nos questionamentos do presente em função da aprendizagem experiencial, por meio da junção entre o saber-fazer e os conhecimentos, que se colocam como possibilidade de transformação e autotransformação do próprio sujeito. Compreendemos, ainda, que escrever é buscar sentido em uma experiência vivida que nos afetou e nos incitou à reflexão e à ação, e tornou-se experiência porque fomos afetados uns pelos outros. Caso contrário, seria somente mais uma informação dentre tantas outras.

Nessa perspectiva, a narrativa de M. S., psicólogo que trabalhou no acolhimento psicológico voluntário por telefone durante a pandemia, atividade exercida junto à Comissão de Promoção de Saúde Mental e promovida pela Universidade do Estado do Amazonas, no período de março a julho de 2020, revelou sua concepção de que a pandemia o colocou em contato real com o fato de que não há controle sobre os fenômenos. Ao ler um texto construído com lembranças dos primeiros atendimentos, M. S. emocionou-se ao relatar frases de diferentes atendimentos feitos por ele:

Alô! Me ajuda, por favor. Tenho sentido falta de ar e pensamentos negativos. Estou assustado, acho que vou enfartar. Tenho a sensação de que vou morrer. Me ajuda, por favor. Não consigo dormir. Não paro de pensar no vírus ...

Alô! Me sinto angustiado. Por favor, tira isso de mim. Estou com medo da morte. Estou vivendo uma realidade que não é a minha. Sinto uma tristeza do nada . . .

Alô! Minha família está abalada com a perda do meu pai. Ninguém conseguiu falar com ele. Ele é cego e só conseguiu dizer que não come porque ninguém dá comida pra ele ...

Alô! Tenho a sensação de que o ar não é mais o mesmo ... (M. S., 20 jul. 2020).

O psicólogo relembrou que, ante as escutas, ficava por horas tomado por diferentes dores. Afirmou que, por vezes, o sofrimento do outro é o sofrimento do terapeuta que, num ato reflexivo, alcançou a compreensão relativa à impermanência e à incerteza sobre o mundo e sobre a vida. No que diz respeito a esse aspecto, ele narrou:

Ao terminar cada noite de atendimento, estava exausto. Agora era eu e a minha ansiedade. Quem vai cuidar de mim? Colocava em prática todo o processo de consciência sobre si, coisas que aprendi com a experiência, para não adoecer diante das incertezas trazidas pela pandemia. Três meses de atendimento e a pandemia foi perdendo força aqui na nossa cidade. Mas deixou suas marcas (M. S., 20 jul. 2020).

A fisioterapeuta intensivista T.M. trouxe, em sua narrativa, o desejo de guardar na memória um período em que ela reconheceu o valor da proximidade relacional com seus pacientes. Essa era a preocupação que lhe causava angústia, amenizada pela comunicação estabelecida com pacientes e familiares por telefone. Relembrou que essa estratégia foi uma saída encontrada por ela para compensar o distanciamento terapêutico. Recordou que, de tudo que experienciou, ". . . a morte dos pacientes sem seus entes queridos o verem é algo surreal de se viver e não existem palavras suficientes para descrever a violência disto" (T. M., 20 jul. 2020).

Ao atribuir novos significados ao que estava vivenciando e com o objetivo de preservar as suas memórias, a fisioterapeuta R. A., residente no estado de Minas Gerais, decidiu escrever um diário de ressonâncias, para registrar os sentimentos despertados nela a cada dia de cuidado prestado às pessoas isoladas por estarem contaminadas por Covid-19. A ação dessa profissional nos revela um empenho em registrar momentos do seu plantão, os quais ela escolheu para perpetuar-se na história de sua vida, apontando-nos o desejo de preservar a memória de um período que desencadeou mudanças no "ser" profissional da área da saúde. Nesse sentido, R. A. relembra que, em meio à paramentação completa que cobria toda a face e o corpo, e que dificultava a comunicação, restou-lhe "sorrir com os olhos". Dessa forma, conseguia transcorrer o plantão com mais leveza, fazendo chegar um cuidado acolhedor àqueles que estavam isolados.

Por meio dessas narrativas, podemos observar que os principais conteúdos memorialísticos desse período não dizem respeito apenas ao transbordamento de medos e 
preocupações inerentes à pandemia. Constatamos que, ao escolher suas lembranças e relatar seus sentimentos e consternações, esses profissionais narraram também seus repertórios de recursos internos, acreditando que suas ações afetavam diretamente a coletividade. Com esse ato, tornavam-se protagonistas nesse processo de enfrentamento.

Compreendemos que a promoção de um espaço de partilha constituiu-se como experiência de cuidado e de preservação da memória daqueles que atuaram no enfrentamento da pandemia. Concordamos com Halbwachs (2003), ao assinalar que o indivíduo isolado de um grupo social não seria capaz de construir qualquer tipo de experiência. Consequentemente, não haveria a possibilidade da manutenção de registro sobre o passado.

\section{Considerações finais}

Cada vez que visitamos nossas memórias, é como se estivéssemos escavando um sítio arqueológico, em que novas informações são agregadas à medida que novas camadas são reveladas. Se colocarmos atenção nesse ato, poderemos (re)construir, vivificar e atribuir novos significados ao ocorrido. Portanto, a memória nos mostra quem nós fomos, nos molda ao mesmo tempo em que nos revela quem nós somos. Isso nos é substrato para o que queremos ser.

A narrativa sensível das experiências e memórias dos profissionais da área da saúde em tempos de pandemia aponta para a adoção de estratégias individuais de enfrentamento do sofrimento, com base no reencontro da interioridade veiculada ao reconhecimento de suas próprias dores e dos novos desafios no exercício da profissão. A narrativa também nos impulsiona a visibilizar e ecoar as histórias dos profissionais da saúde que, certamente, pelo teor do sofrimento anunciado e denunciado, podem ser silenciadas, ignoradas ou descredibilizadas por discursos gerencialistas/institucionais oficiais, quando tivermos o cenário pandêmico finalizado.

Sabedores de que, segundo a literatura, o sofrimento laboral é culturalmente sonegado nas instituições brasileiras, demarcar as experiências de ser da saúde no contexto da pandemia pode ampliar nossa compreensão acerca dos esforços dos trabalhadores em corresponderem às expectativas institucionais e sociais. Compreenderemos também os adoecimentos gerados, dentre outras ocorrências, pela redução de estratégias institucionais contínuas de proteção e promoção de saúde mental e pela fragilidade dos planos gestores em organizar em rede o trabalho de enfrentamento e combate da pandemia.

No contexto sociopolítico em que saúde pública tem o orçamento diminuído e mostrase objeto de comunicações contraditórias, incluindo dilemas com mensagens opostas e veiculação de notícias falsas, as biografias e narrativas dos trabalhadores da saúde evidenciam os "nós" enfrentados na linha de frente. Mostram ainda o zelo para desatar esses "nós" e conferir abrigo às dificuldades, potencializando as capacidades dos profissionais de saúde que estão na linha de frente no combate à pandemia, para "fazer frente" às necessidades de cuidado apresentadas por seus pacientes e para preservar/cultivar sua saúde mental em contexto tão adverso. O "Nós" mostrou a pluralidade de engates e desates de "nós", em forma de laços solidários, respeitosos e acolhedores.

Agradecimentos: aos profissionais da linha de frente; aos extensionistas da UEA; à revisora Zezé Bacelar.

\section{Referências}

Bao, Y., Sun, Y., Meng, S., Shi, J., \& Lu, L. (2020). 2019-nCoV epidemic: address mental health care to empower society. The Lancet, 395(10224), 22-28. https://doi.org/10.1016/S0140-6736(20)30309-3 
Bateson, G., Jackson, D. D., Haley, J., \& Weakland, J. (1956). Toward a theory of schizophrenia. Behavioral Science, 1, 251-264. https://doi.org/10.1002/bs.3830010402

Bonet, O. (2004). Saber e sentir: uma etnografia da aprendizagem da biomedicina (20a ed.). Fiocruz. https://portal.fiocruz.br/livro/saber-e-sentir-uma-etnografia-da-aprendizagem-da-biomedicina

Bosi, E. (1994). Memória e sociedade: lembranças de velhos. Companhia das Letras.

Carvalho, R. (2000, 15 abril). Amazonas apresenta colapso no sistema de saúde por causa do coronavírus. Estadão. https://saude.estadao.com.br/noticias/geral,amazonas-apresenta-colapso-no-sistema-de-saude-por-causado-coronavirus, 70003272136

Crepaldi, M. A., Schmidt, B., Noal, D. S., Bolze, S. D. A., \& Gabarra, L. M. (2020). Terminalidade, morte e luto na pandemia de Covid-19: demandas psicológicas emergentes e implicações práticas. Estudos de Psicologia (Campinas), 37, 1-12. https://doi.org/10.1590/1982-0275202037e200090

Dejours, C. (2017). Psicodinâmica do trabalho: casos clínicos. Dublinense.

Dejours, C., Deranty, J. P., Renault, E., \& Smith, N. (2018). The return of work in critical theory: self, society, politics. Columbia University Press.

Duan, L., \& Zhu, G. (2020). Psychological interventions for people affected by the Covid-19 epidemic. Lancet Psychiatry, 7(4), 300-302. https://www.ncbi.nlm.nih.gov/pmc/articles/PMC7128328/

Figley, C. R. (1995). Compassion fatigue as secondary traumatic stress disorder: an overview. In C. R. Figley (Ed.), Compassion fatigue (pp.1-20). Brunnar/Mazel.

Halbwachs, M. (2003). A memória coletiva. Centauro.

Honorato, E. J., Neves, A. L. M., Therense, M., Martins, G. C., Marangoni, V., S. L., Silva, T. A., Souza, D. C., Costa, L. V., \& Lemos, S. M. (2020). Waves of mental health Demands during the Covid-19 pandemic. Research, Society and Development, 9, e767986204.

Kavoor, A. R., Chakravarthy K., \& John, T. (2020). Remote consultations in the era of Covid-19 pandemic: preliminary experience in a regional Australian public acute mental health care setting. Asian Journal of Psychiatry, 51, 102074. https://doi.org/10.1016/j.ajp.2020.102074

Lima, B. (2020, 26 maio). Brasil assume a liderança do ranking de mortes diárias por Covid-19. Correio Brasiliense. https://www.correiobraziliense.com.br/app/noticia/brasil/2020/05/26/interna-brasil,858246/brasil-assume-alideranca-do-ranking-de-mortes-diarias-por-Covid-19.shtml

Machado, L. V., \& Boarini, M. L. (2013). Políticas sobre drogas no Brasil: a estratégia de redução de danos. Psicologia: Ciência e Profissão, 33(3), 580-595.

Mamun, M. A., \& Griffiths, M. D. (2020). First Covid-19 suicide case in Bangladesh due to fear of Covid-19 and xenophobia: possible suicide prevention strategies. Asian Journal of Psychiatry, 51, 102073. https://doi.org/10.1016/j.ajp.2020.102073

Marques, P. (2020, 02 agosto). Amazonas. Em julho, interior do AM registrou maior número de novos casos de Covid19 desde o início de pandemia. Globo Notícias, G1. https:/g1.globo.com/am/amazonas/noticia/2020/08/02/em-julho-interior-do-am-registrou-maior-numerode-novos-casos-de-Covid-19-desde-inicio-de-pandemia.ghtml

Ministério da Saúde. (2020). Covid-19. Painel Coronavírus. https://covid.saude.gov.br/

Ministério da Saúde. (2021). Coronavírus/Brasil. Painel Coronavírus. https://covid.saude.gov.br/

Parkes, C. M. (2009, 4 julho). Amor e perda: as raízes do luto e suas complicações. Summus.

Globo Notícias, G1. (2020). RN registra 33.910 casos confirmados de Covid-19 e 1.200 mortes pela doença. Globo Notícias, G1. https://g1.globo.com/rn/rio-grande-do-norte/noticia/2020/07/04/rn-registra-33910-casosconfirmados-de-Covid-19-e-1200-mortes-pela-doenca.ghtml 
Schmidt, B., Crepaldi, M. A., Bolze, S. D. A., Neiva-Silva, L., \& Demenech, L. M. (2020). Saúde mental e intervenções psicológicas diante da pandemia do novo coronavírus (Covid-19). Estudos de Psicologia (Campinas), 37, e200063. https://doi.org/10.1590/1982-0275202037e200063

Shear, M. K. (2015). Complicated grief. The New England Journal of Medicine, 372, 153-160. https://doi.org/10.1056/NEJMcp1315618

Souza, E. C. (2004). História de vida, narrativas, conhecimento de si, representações da docência. In M. H. M. B. Abrahão (Org.), A aventura (auto) biográfica: teoria e empiria (pp. 201-224). EDIPUCRS.

Travagin, L. B. (2017). O avanço do capital na saúde: um olhar crítico às Organizações Sociais de Saúde. Saúde Debate, 41(115). https://doi.org/10.1590/0103-1104201711501

Vivian, C., Trindade, L., Rezer, R., Vendruscolo, C., \& Rodrigues Junior, S. (2019). Estratégias de defesa contra o sofrimento no trabalho de docentes da pós-graduação stricto sensu. Cadernos de Psicologia Social do Trabalho, 22 (2), 217-234. https://doi.org/10.11606/issn.1981-0490.v22i2p217-234

Worden, J. W. (2013). Aconselhamento do luto e terapia do luto: um manual para profissionais de saúde mental. Roca.

Endereço para correspondência

therense@gmail.com
Recebido em: 02/12/2020

Revisado em: 05/10/2021

Aprovado em: 21/10/2021 